\title{
Endoplasmic Reticulum Mediated Necrosis-like Apoptosis of HeLa Cells Induced by $\mathrm{Ca}^{2+}$ Oscillation
}

\author{
Qingliu Hu ${ }^{\dagger}$, Junlei Chang ${ }^{\dagger}$, Litao Tao ${ }^{\ddagger}$ Guoliang Yan*, Mingchao Xie ${ }^{\dagger}$ and Zhao Wang ${ }^{\dagger, * *}$ \\ 'Medical School, Tsinghua University, Beijing 100084, People's Republic of China \\ Department of Biological Sciences and Biotechnology, Tsinghua University, Beijing 100084, People's Republic of China
}

Received 1 August 2005, Accepted 16 September 2005

\begin{abstract}
Apoptosis and necrosis are distinguished by modality primarily. Here we show an apoptosis occurred instantly, induced by $300 \mu \mathrm{M}$ W-7 ((N-(6-aminohexyl)-5-chloro-1naphthalenesulfonamide hydrochloride), inhibitor of calmodulin), which demonstrated necrotic modality. As early as $30 \mathrm{~min}$ after W-7 addition, apoptotic (sub-diploid) peak could be detected by fluorescence-activated cell sorter (FACS), "DNA ladders" began to emerge also at this time point, activity of caspase-3 elevated obviously within this period. Absence of mitochondrial membrane potential (MMP) reduction and cytochrome $c$, AIF (apoptosis inducing factor) release, verified that this rapid apoptosis did not proceed through mitochondria pathway. Activation of caspase-12 and changes of other endoplasmic reticulum (ER) located proteins ascertained that ER pathway mediated this necrosis-like apoptosis. Our findings suggest that it is not credible to judge apoptosis by modality. Elucidation of ER pathway is helpful to comprehend the pathology of diseases associated with ER stress, and may offer a new approach to the therapy of cancer and neurodegenerative diseases.
\end{abstract}

Keywords: Apoptosis, Caspase-12, Endoplasmic reticulum, Mitochondria, Necrosis, W-7

\section{Introduction}

$\mathrm{Ca}^{2+}$ is a universal messenger regulating many physiological functions including such an important one, as the ability of the cell to undergo orderly self-destruction upon completion of its mission, called apoptosis. If this function is compromised unwanted cells may eventually take over the tissue turning it

\footnotetext{
* To whom correspondence should be addressed.

Tel: 86-10-62772241; Fax: 86-10-62772240

E-mail: zwang@tsinghua.edu.cn
}

into a cancer. $\mathrm{Ca}^{2+}$ dependency of apoptosis, when its all aspects are learned and understood and key molecular players identified, may provide a good opportunity for controlling tumor growth. $\mathrm{Ca}^{2+}$ overload in cytosolic and mitochondria has been suggested to contribute to apoptosis of many cancer cell types and neurodegenerative diseases. Apoptosis is a common, conserved, endogenous cell suicide program required for proper embryonic development and maintenance of homeostasis in adult tissues. It is characterized by a biochemical cascade and morphological changes, including blebbing, shrinkage, nuclear condensation and internucleosomal cleavage of DNA ("DNA ladders"). Although it is not seen in all cell types undergoing apoptosis, the presence of the "DNA ladders" has long been recognized as a hallmark feature of apoptosis. Caspases (especially caspase-3) activation has been considered to be a putative molecular marker of apoptosis. On the contrary, necrotic cells demonstrate as swelling of whole cell and organelles, dispersion of nucleus and random cleavage of DNA (DNA smear), etc, without shrinkage, activation of caspases and sub-diploid (apoptotic) peak measured by fluorescence-activated cell sorter (FACS). Although programmed cell death (PCD) has often been equated with apoptosis, it has become increasingly clear that non-apoptotic PCD also exists, particularly in individual development and neuro-degenerative diseases. For instance, T9 glioma cells expressing membrane macrophage colony-stimulating factor werekilled by polymorphonuclear leukocytes and macrophages with vacuolization of the mitochondria and endoplasmic reticulum(ER) resembling paraptosis which differs from those of apoptosis and involves cytoplasmic vacuolation, mitochondrial swelling and absence of caspases activation or typical nuclear changes, including pyknosis and DNA fragmentation (Chen et $a l ., 2002)$. Another cell death type oncosis which is marked by cellular swelling, organelle swelling, blebbing, vacuolization, increased membrane permeability, and karyolysis, refers to a pre-mortal process, whereas the term necrosis refers to the morphological alterations appearing after cell death (Van and Van, 2002). These examples support the theory that cells have 
other intrinsic programs for death that are distinct from apoptosis. Apoptosis typically proceeds through one of two general signaling pathways, namely the extrinsic apoptotic pathway or the intrinsic apoptotic pathway (Tornquist, 1993). Although mitochondria pathway is involved in most of apoptosis and has been elucidated minutely, there has been some controversy over the role of mitochondria in apoptosis. Recent studies have suggested the existence of a novel apoptotic pathway in which caspase-12 functions as the initiator caspase in response to a toxic insult to the ER (Liu et al., 1996). It was discovered that caspase-12 can activate caspase-9 without involvement of cytochrome $c$, and that ER stress triggers a specific cascade involving caspase-12, -9 , and -3 in a cytochrome $c$-independent manner (Nakagawa et al., 2000). So except for the two well-known apoptotic pathways, there exists another intrinsic apoptotic pathway - ER pathway which is poorly elucidated by now. We discovered that high concentration $(\geq 600 \mu \mathrm{M}) \mathrm{W}-7$ (Sigma, US) induced necrosis of Hela cells (data not shown), middle concentration (300 $\mu \mathrm{M}) \mathrm{W}-7$ induced apoptosis, low concentration of $(\leq 50 \mu \mathrm{M})$ W-7 had no effect (data not shown). As was in accordance with that reported (Jan and Tseng, 2000). $300 \mu \mathrm{M} \mathrm{W}-7$ induced typical "DNA ladders" which is hallmark of apoptosis, so this dosage was chosen as Hela cell apoptosis inducer in our experiments. Here we lay out a rapid apoptosis of Hela cells insulted by $300 \mu \mathrm{M} \mathrm{W}-7$, which is similar to necrosis morphologically. This rapid apoptosis was mediated by ER pathway which was elucidated in detail in this paper.

\section{Materials and Methods}

Cell cycle analysis Proceed as described (Liu et al., 2004). After treatment with $300 \mu \mathrm{M} \mathrm{W}-7$ or $30 \mu \mathrm{M}$ calpeptin and $300 \mu \mathrm{M} \mathrm{W}-7$ for indicated times, Hela cells were harvested and washed with phosphate-buffered solution (PBS), then fixed in cold $70 \%$ ethanol for at least $2 \mathrm{~h}$. Deposited and incubated in RNase A/PBS (100 $\mu \mathrm{g} /$ $\mathrm{ml}$ ) at $37^{\circ} \mathrm{C}$ for $30 \mathrm{~min}$, then re-suspended in staining buffer (3.8 $\mathrm{mM}$ sodium citrate, $0.01 \mathrm{mg} / \mathrm{ml}$ propidium iodide, Sigma, US) and incubated at $2-8^{\circ} \mathrm{C}$ in dark for $1 \mathrm{~h}$. Finally, the stained cells were analyzed with fluorescence-activated cell sorter (FACS) (FACSCalibur, Becton Dickinson, US) using CELLQuest software (Becton Dickinson, US). 15,000 events were analyzed for each sample.

DNA fragmentation analysis Proceed as described (Liu et al., 2004). The untreated and treated cells were harvested and lysed in $100 \mu \mathrm{l}$ buffer $(10 \mathrm{mM}$ Tris-HCl, pH 7.4, $10 \mathrm{mM}$ EDTA, pH 8.0, $0.5 \%$ Triton $\mathrm{X}-100)$. The supernatant was acquired through centrifugation at $14,000 \mathrm{~g}$ for $10 \mathrm{~min}$ and then incubated with RNase A $(200 \mu \mathrm{g} / \mathrm{ml})$ at $37^{\circ} \mathrm{C}$ for $60 \mathrm{~min}$. Proteins were removed by incubation with Proteinase $\mathrm{K}(200 \mu \mathrm{g} / \mathrm{ml})$ at $50^{\circ} \mathrm{C}$ for $30 \mathrm{~min}$. The supernatant was added with $20 \mu \mathrm{l} 5 \mathrm{M} \mathrm{NaCl}$ and $120 \mu \mathrm{l}$ isopropanol. After deposition at $-20^{\circ} \mathrm{C}$ for $12 \mathrm{~h}$, the precipitated DNA pellet was dissolved in distilled water, then electrophoresed in a $1.5 \%$ agarose gel, stained with ethidium bromide (Sigma, US), and photographed under UV illumination.
Measurement of $\left[\mathrm{Ca}^{2+}\right]_{i}$ After an overnight period of attachment in glass bottom microwell dishes (MatTek, US), the cells were loaded for $30 \mathrm{~min}$ at $37^{\circ} \mathrm{C}$ with $5 \mu \mathrm{M}$ Fluo-3 AM [4-(6-acetoxymethoxy2,7-dichloro-3-oxo-9-xanthenyl)-4'-methyl-2,2' (ethylenedioxy) dianiline-N,N,N',N'-tetraacetic acid tetrakis (acetoxymethyl) ester, Sigma, US] in RPMI1640 medium contained 5\% FBS. The cells were then washed with PBS to remove extracellular Fluo-3 AM and refilled with $1 \mathrm{ml}$ RPMI 1640 medium with $5 \%$ FBS. $\left[\mathrm{Ca}^{2+}\right]_{i}$ changes in individual cells were imaged before and after reagents addition, with Nikon TE300 inverted microscope $(\times 40$ objective lens). Cells were excited at $480 \mathrm{~nm}$ at $5 \mathrm{~s}$ intervals using a Till photonics monochromator, and emission signals were detected at $515 \mathrm{~nm}$ with an Imago SensiCam cooled charge-coupled device camera (software, Metafluo Version 4.5 rO).

Electron microscopy (TEM) Treated Hela cells were fixed in $2.5 \%$ glutaraldehyde diluted with $0.2 \mathrm{M}$ PBS, $\mathrm{pH} 7.2$, then washed in cacodylate buffer containing $7.2 \%$ sucrose. After post-fixed in $1 \%$ osmium tetroxide for $100 \mathrm{~min}$, cells were dehydrated in graded acetone and embedded in Epon. Ultrathin sections of cells were stained with uranyl acetate and lead citrate, then examined and photographed with a JEM-1230 (JEOL, Japan) transmission electron microscope (TEM).

Cytosolic fractionation Proceeded as described (Single et al., 1998). Cells were washed in PBS and lysed by digitonin buffer (75 $\mathrm{mM} \mathrm{NaCl}, 8 \mathrm{mM} \mathrm{Na} \mathrm{HPO}_{4}, 1 \mathrm{mM} \mathrm{NaH} \mathrm{PO}_{4}, 1 \mathrm{mM}$ EDTA, 250 $\mathrm{mM}$ sucrose, $35 \mu \mathrm{g}$ digitonin $/ 4 \times 10^{6}$ cells). Heavy organelles and cell debris were deposited by centrifuging at $14,000 \mathrm{~g}$ for $2 \mathrm{~min}$. The supernatants were frozen at $-70^{\circ} \mathrm{C}$ waiting for Western blotting analysis.

Measurement of mitochondrial membrane potential Proceed as described (Liu et al., 2004). Mitochondrial energization was determined by the retention of the dye $\mathrm{DiOC}_{6}$ (3) (Sigma, US). Cells were harvested and washed twice with PBS. After incubation with $50 \mathrm{nM} \mathrm{DiOC}_{6}(3)$ at $37^{\circ} \mathrm{C}$ for $30 \mathrm{~min}$, the cells were washed again and analyzed with FACS.

Assessment of caspases activity ApoAlert caspase fluorescent assays (Clontech, US) were used to determine the enzymic activity of caspases-3, -8 , and -9 . The assessment of caspases activities was proceeded as guideline of ApoAlert caspase fluorescent assays kits.

Western blot Proteins were normalized to $50 \mu \mathrm{g} /$ lane, fractioned by $(10.0 \%$ for caspase- 12 antibody; $12.5 \%$ for caspase- 3 and -8 , AIF, Bcl-xL, calreticulin, $\beta$-actin and PTP-1B antibodies; $15.0 \%$ for caspase-9 and Cyt $c$ antibodies; same concentrations as corresponding other antibodies for $\beta$-tubulin.) polyacrylamide gels, other procedures were proceeded as described (Reddy et al., 2004). (Cyt $c$ antibody was purchased from R\&D, US; PTP-1B were from Upstate co., US; and other antibodies were from Sigma, US.)

Cytoskeleton staining Hela cells were cultivated in glass bottom microwell dishes. After treatment with $300 \mu \mathrm{M} \mathrm{W}-7$ and (or without) $30 \mu \mathrm{M}$ calpeptin (Alexis, US), Cells were fixed by $4 \%$ formaldehyde/PBS solution, and incubated with $0.1 \%$ Triton $\mathrm{X}$ 100/PBS solution before staining with $20 \mu \mathrm{M}$ Phalloidin-TRITC 
(Phalloidin-Tetramethylrhodamine B isothiocyanate, Sigma, US) for $20 \mathrm{~min}$ in dark. Finally the stained cells were photographed by Leica fluorescent microscope (DMIRB, Germany).

\section{Results}

$300 \mu \mathrm{M}$ W-7 induced rapid apoptosis of Hela cells In our experiments, $300 \mu \mathrm{M} \mathrm{W}-7$ induced instant $\left[\mathrm{Ca}^{2+}\right]_{\mathrm{i}}$ (calcium concentration in cytoplasm) increase of Hela cells in cultivation medium [RPMI1640 medium contained 5\% fetal bovine serum (FBS)], demonstrated by calcium imaging system (Fig. 1A). Cell shrinkage and apoptotic bodies could be seen at 1,000 s after W-7 addition (Fig. 1A). Apoptotic peak could be detected by FACS as early as 30 min after W-7 addition (Fig. 1B), DNA ladders began to emerge also at this time point (Fig. 1C), activity of caspase-3 elevated obviously within this period, although no obvious elevation of caspase-8, -9 activity was measured (Fig. 1D). These results indicated that this rapid demise of Hela cells induced W-7 was apoptosis seldom reported.

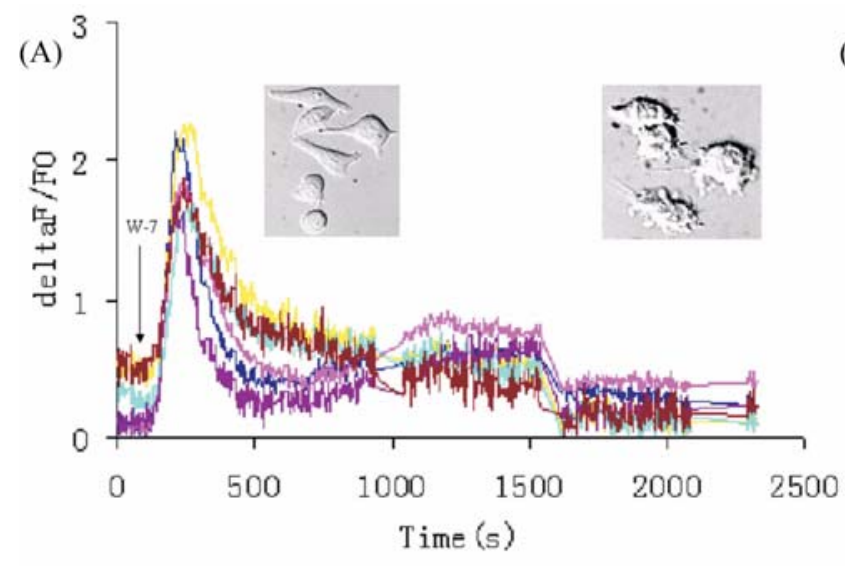

(C) $\quad \begin{array}{lllllll}\mathrm{W}-7 & 0 & 5 & 10 & 30 & 120 & 240(\mathrm{~min})\end{array}$

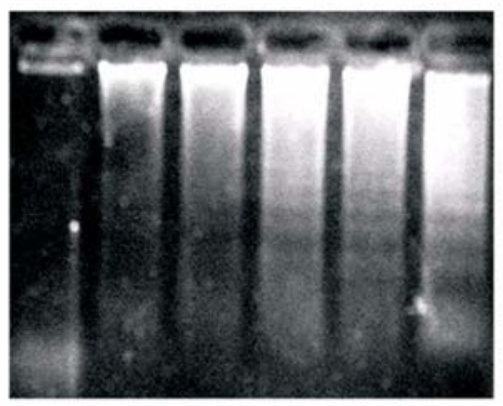

Rapid apoptosis of Hela cells induced with $300 \mu \mathrm{M}$ W-7 demonstrated necrotic modality Morphological study of this rapid apoptosis by transmission electron microscope (TEM) demonstrated that vacuoles scattered all over the cytosol, nucleus shrank and cell membrane was ruptured, although mitochondria still kept sane, at 5 min after $\mathrm{W}-7$ addition (Fig. 2). At $30 \mathrm{~min}$ after $\mathrm{W}-7$ addition, swelled mitochondria and ER scattered all over cytosol, and some nuclei broke. No nucleus pyknosis happened during the whole process (Fig. 2). In a word, morphological changes of Hela cells severely insulted by $300 \mu \mathrm{M} \mathrm{W}-7$ was not typical apoptotic, but similar to necrosis. We surmised that this rapid apoptosis might proceed through a novel signal pathway different from classical ones (death receptor pathway and mitochondria pathway).

The necrosis-like rapid apoptosis of Hela cells was not mediated by mitochondria pathway In order to judge whether did this rapid apoptosis proceed through mitochondria pathway, the loss of mitochondrial membrane potential
(B)
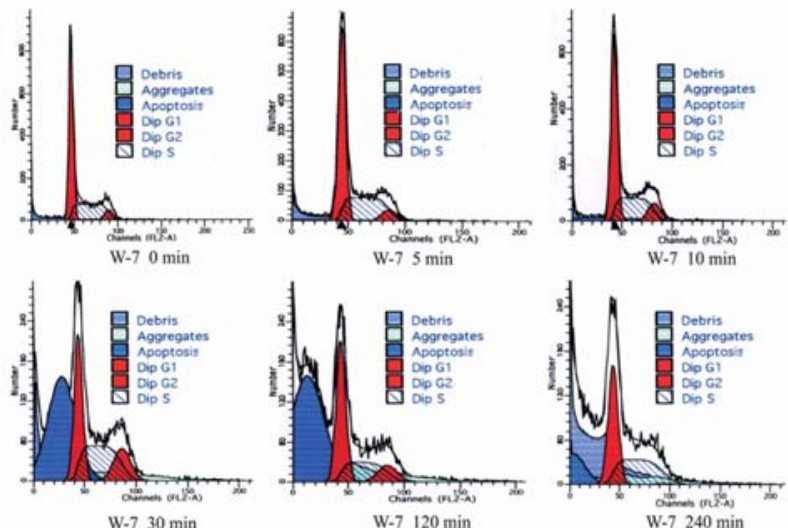

(D)

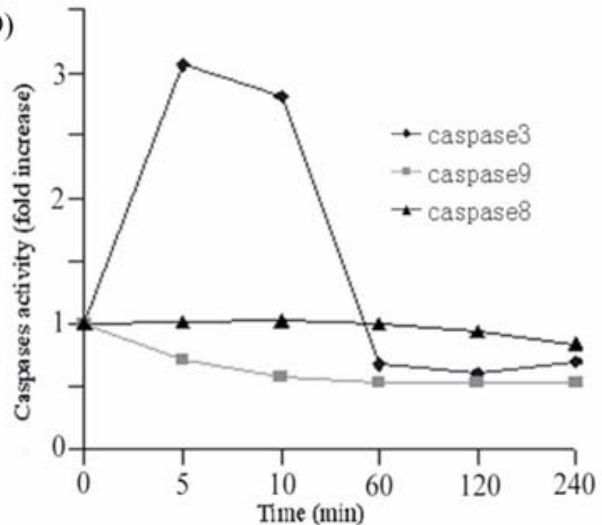

Fig. 1. Cell death induced by $300 \mu \mathrm{M}$ W-7 was rapid apoptosis. (A) $300 \mu \mathrm{M} \mathrm{W}-7$ induced temporal $\left[\mathrm{Ca}^{2+}\right]_{\mathrm{i}}$ increase (each curve stands for $\left[\mathrm{Ca}^{2+}\right]_{i}$ oscillation in each cell) in RPMI1640 medium contained 5\% FBS, blebbing, shrinkage and apoptotic bodies could be observed at 1,000 s after W-7 addition. Figures above the graph of panel A are representations of cells before addition of W-7 and at 1000 seconds after addition. (B) Apoptotic (blue) peak could be detected by FACS as early as 30 min after W-7 addition, (C) DNA ladders began to emerge also at this time point. (D) Activity of caspase-3 elevated obviously within this period, no obvious activity elevation of caspase-8, -9 was measured after W-7 incubation. Panels B-D are from the same experimental treatments, and representatives of four separate determinations. 

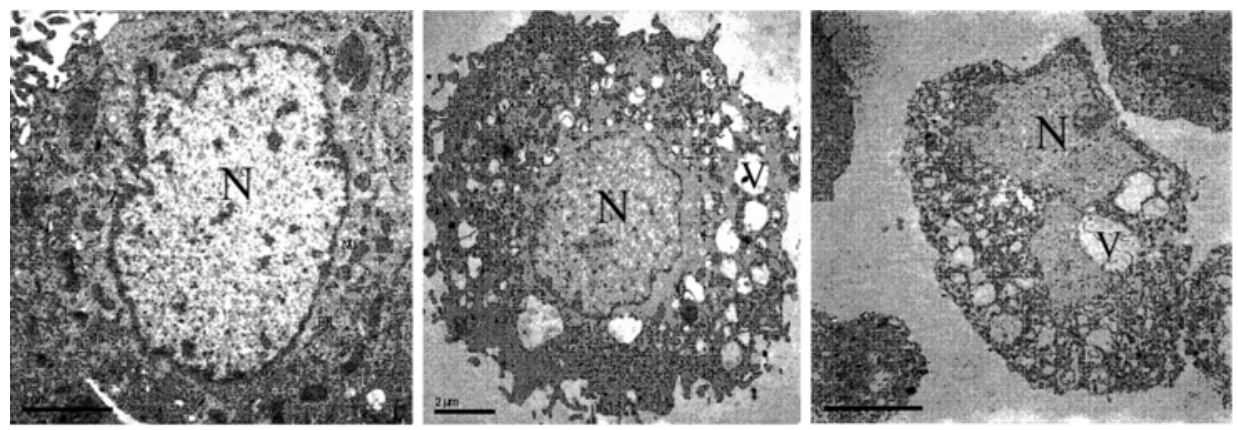

W-7 0 min(bar length, $2 \mu \mathrm{m}) \mathrm{W}-75 \mathrm{~min}$ (bar length, $2 \mu \mathrm{m}) \mathrm{W}-730 \min ($ bar length, $5 \mu \mathrm{m})$
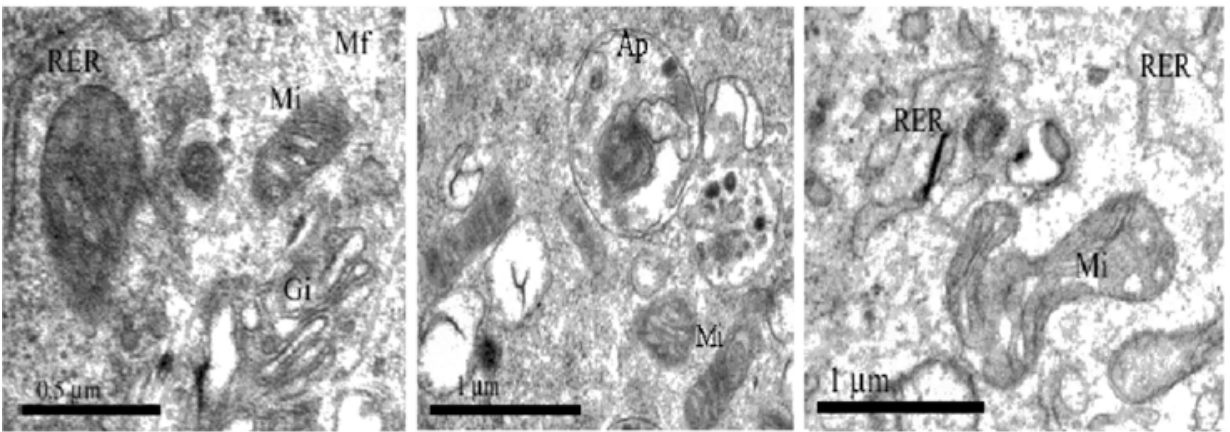

W-7 0 min(bar length, $0.5 \mu \mathrm{m}) \quad W-75 \min ($ bar length, $1 \mu \mathrm{m}) \quad W-730 \min ($ bar length, $1 \mu \mathrm{m})$

Fig. 2. Rapid apoptosis of Hela cells induced with $300 \mu \mathrm{M}$ W-7 demonstrated necrotic modality. Vacuoles began to emerge, nucleus shrank, autophagy happened in cytoplasm, cell membrane and cytoplasm were ruptured, although mitochondria still kept sane, at 5 min after W-7 addition. Swelled mitochondria and ER scattered all over cytoplasm, some nuclei broke at 30 min after W-7 addition. No chromatin congregation happened throughout the whole process. All are representatives of three separate determinations. N, nucleus; Ap, autophage; Mi, mitochondria; Gi, Golgi apparatus; RER, rough endoplasmic reticulum; Mf, microfilament; V, vacuole.

(A)

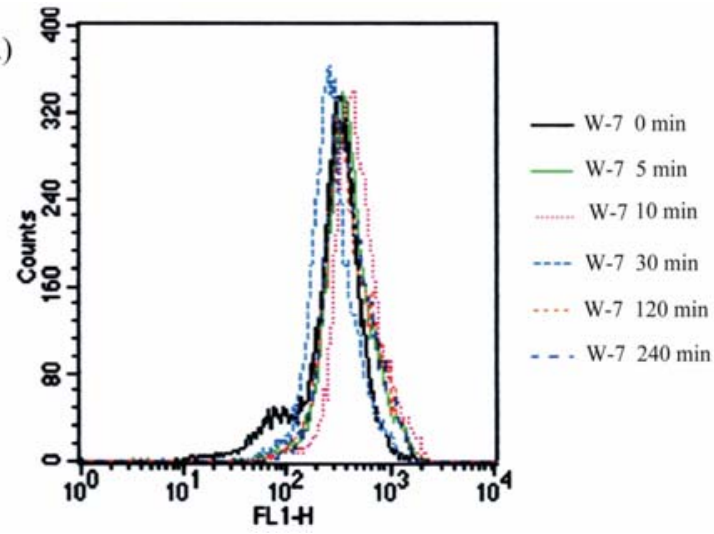

(B)

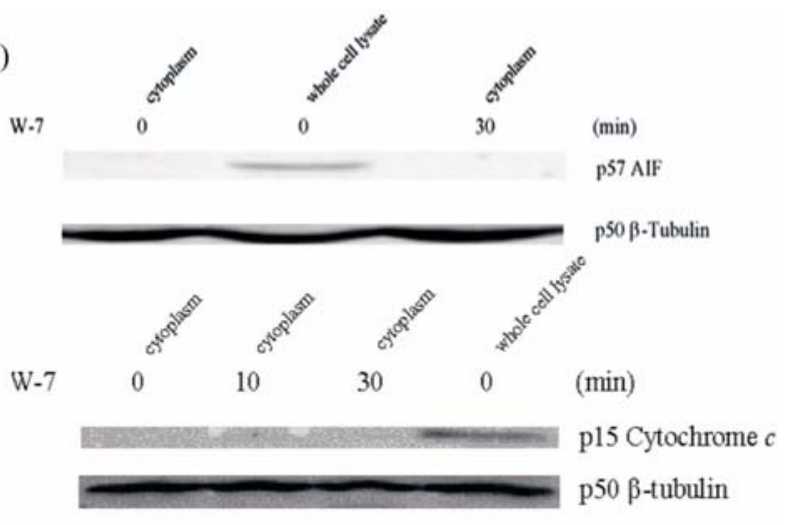

Fig. 3. The rapid apoptosis of Hela cells did not proceed through mitochondria pathway. (A) No change in mitochondrial DiOC6(3) uptake was detected by FACS after W-7 treatment of the Hela cells indicating that the mitochondrial membrane potential did not change. (B) No release of Cyt $c$ and AIF was detected in apoptotic Hela cells insulted by W-7. Panels A-B are representatives of three separate determinations.

(MMP, $\Delta \Psi \mathrm{m}$ ) was measured by FACS, release of Cyt $c$ and AIF was detected by western blot. Results ascertained that no reduction of $\Delta \Psi \mathrm{m}$ (Fig. 3A) and release of Cyt $c$, AIF (Fig. $3 \mathrm{~B}$ ) occurred during the whole process. Therefore, this rapid apoptosis did not proceed through mitochondria pathway.

$\left[\mathrm{Ca}^{2+}\right]_{i}$ elevation in Hela cells induced with $300 \mu \mathrm{M}$ W-7 was mainly caused by release of $\mathrm{ER} \mathrm{Ca}^{2+}$ store The initial inducement of this rapid apoptosis was calcium oscillation in cytosol, as shown in experiments (Fig. 1A), so ascertainment of $\mathrm{Ca}^{2+}$ source affecting calcium oscillation is helpful for estimating possible signal pathway involved. Calcium imaging demonstrated that no obvious $\left[\mathrm{Ca}^{2+}\right]_{\mathrm{i}}$ elevation was caused by W-7 after ER $\mathrm{Ca}^{2+}$ store was depleted by $2 \mu \mathrm{M}$ thapsigargin (Tg), suggesting that $\left[\mathrm{Ca}^{2+}\right]_{i}$ elevation in Hela cells was mainly caused by release of intracellular ER $\mathrm{Ca}^{2+}$ store (Fig. 4A). So 

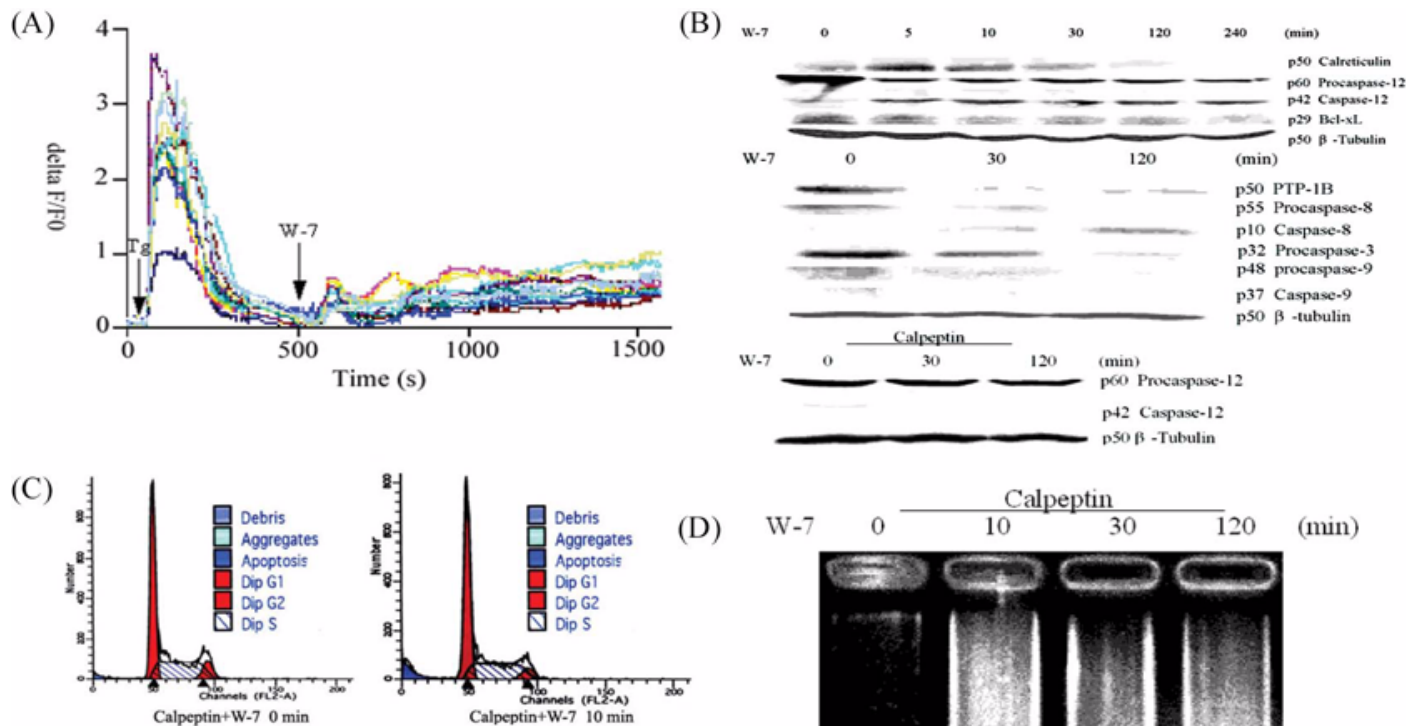

(D)
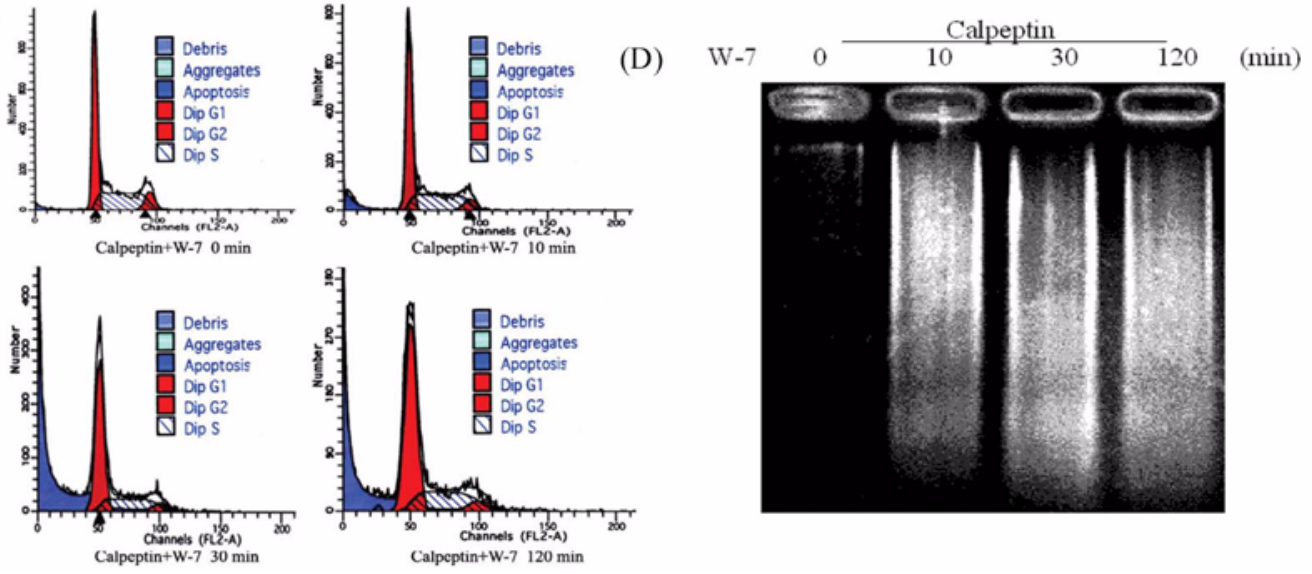

Fig. 4. ER pathway was the only one which mediated this rapid apoptosis of Hela cells. (A) No obvious $\left[\mathrm{Ca}^{2+}\right]_{\mathrm{i}}$ elevation was caused by W-7 after ER $\mathrm{Ca}^{2+}$ store was depleted by $2 \mu \mathrm{M}$ thapsigargin $(\mathrm{Tg})$, suggesting that $\left[\mathrm{Ca}^{2+}\right]_{\mathrm{i}}$ elevation in Hela cells was mainly caused by release of ER calcium store. (B) Western blot of proteins associated with ER pathway demonstrated that calreticulin increased instantaneously, then decreased from $30 \mathrm{~min}$ after $\mathrm{W}-7$ addition, caspase-12, -8 ,-3 were activated, Bcl-xL and PTP-1B were degenerated, no activation of caspase-9 was detected, in Hela cells treated with W-7. (B) After application of $30 \mu \mathrm{M}$ calpeptin (inhibitor of Calpain), cleavage of procaspase-12 induced by W-7 was stopped, (C) apoptotic (sub-diploid, blue) peak could not be detected by FACS at all time points, (D) neither "DNA ladders" (but "DNA smear") emerged at these time points. Hela cells was incubated with calpeptin half an hour ahead of W-7 treatment, when calpeptin was used. Panels C-D are from the same experimental treatments. All panels are representatives of three separate determinations.

we speculated that this rapid apoptosis sprung by $\mathrm{Ca}^{2+}$ oscillation was possibly mediated by ER.

ER pathway was the only one which mediated this rapid apoptosis of Hela cells Procaspase-12 is only localized on $\mathrm{ER}$, its active form-caspase-12 is a key initiator caspase of ER pathway in apoptosis, so detection of caspas-12 activation is pivotal to estimate whether did the rapid apoptosis proceed through ER pathway. Results in our experiments showed that procaspase-12 was cleaved and PTP-1B (protein tyrosine phosphatase 1B, substrate of calpain) degenerated in apoptotic Hela cells induced with W-7 (Fig. 4B), suggesting that this rapid apoptosis of Hela cells did proceed through ER pathway. Calpeptin (inhibitor of calpain) stopped the cleavage of procaspase-12 (Fig. 4B) and abolished apoptosis induced with W-7, turned apoptosis to necrosis (Fig. 4C and 4D). This means ER pathway was the only one involved in this rapid apoptosis.

Other molecules took part in this ER pathway Besides caspase-12, downstream caspases and other molecules involved with regulation of $\mathrm{ER} \mathrm{Ca}^{2+}$ store was measured by western blot. In our experiments, calreticulin, an ER resident protein, increased immediately, then decreased from $30 \mathrm{~min}$ after W-7 addition (Fig. 4B), swelled mitochondria and ER emerged at the same time point (Fig. 2). Downstream caspases, such as caspase- 8 and caspase- 3 were activated (Fig. 4B), whereas cleavage of procaspase- 9 and activity elevation of caspase-9 was not detected (Fig. 4B and 1D). Western blot also showed that $\mathrm{Bcl}-\mathrm{xL}$, an important regulator of carcinogenesis and apoptosis, decreased along with incubation time of W-7 (Fig. 4B).

Cytoskeleton disrupted early in apoptotic Hela cells induced with $300 \mu \mathrm{M}$ W-7 Besides activation of caspases in early apoptotic stage, cytoskeleton is also involved. It was reported that in the initial stages of apoptosis, a fine meshwork of actin filaments turned into actin granules that, in the final stages, were transformed into a network of long actin fibres distributed throughout the cytoplasm, but microtubules were not actively involved (Veselska et al., 2003). In our 
(A)

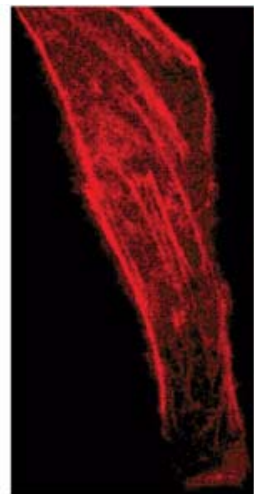

Normal Hela cell

(B) $W-7$

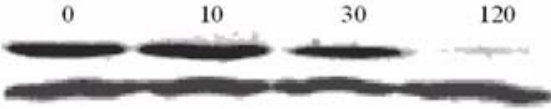

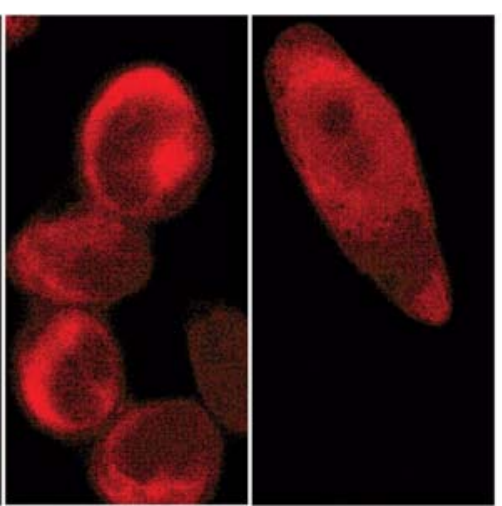

Calpentin+W-7 10 min

$(\min )$

$\beta$-Actin

$\beta$-Tubulin

Fig. 5. Cytoskeleton disrupted early in apoptotic Hela cells induced with $300 \mu \mathrm{M}$ W-7 and necrotic Hela cells treated with $30 \mu \mathrm{M}$ calpeptin and $300 \mu \mathrm{M}$ W-7. (A) Bundles of microfilaments could be seen clearly all over the whole normal Hela cell, but disrupted in apoptotic Hela cell induced with W-7 and necrotic cell by calpeptin $+\mathrm{W}-7$, no bundles of microfilaments could be seen in these cells. (B) Western blot demonstrated that $\beta$-actin was degenerated, but no degeneration of $\beta$-tubulin occurred in apoptotic Hela cells. Panels A-B are representatives of three separate determinations.

study, bundles of microfilaments could be seen clearly all over the whole normal Hela cell, but disrupted in apoptotic Hela cells induced with $\mathrm{W}-7$ and necrotic cells by calpeptin $+\mathrm{W}-7$, no bundles of microfilaments could be seen in these cells at 10 min after drug addition (Fig. 5A). Western blot demonstrated that $\beta$-actin was degenerated, but no degeneration of $\beta$-tubulin occurred in these apoptotic cells (Fig. 5B).

\section{Discussion}

$\mathrm{Ca}^{2+}$ signals control key biological functions, including fertilization, development, cardiac contraction, and secretion of neurotransmitters and hormones (Berridge et al., 2000). At the cellular level, $\mathrm{Ca}^{2+}$ can be either a life and death signal, as changes in cytosolic free $\mathrm{Ca}^{2+}$ concentration can control cell growth and proliferation or induce apoptosis (Berridge et al., 1998). These diverging effects reflect the precise spatial and temporal encoding of $\mathrm{Ca}^{2+}$ signals, which depends largely on the controlled release of $\mathrm{Ca}^{2+}$ from intracellular organelles. The main $\mathrm{Ca}^{2+}$ intracellular store is ER which was released by $\mathrm{W}-7$, as been shown in our experiments. Thapsigargin $(\mathrm{Tg})$ is extracted from the plant Thapsia garganica L. and an effective inhibitor of the $\mathrm{Ca}^{2+}$ ion pump proteins of intracellular membranes located in sarcoplasmic reticulum (SR) and endoplasmic reticulum (ER) of skeletal, cardiac, muscle and brain microsomes (Kijima et al., 1991; Lytton et al., 1991). Tg

was often used to release intracellular $\mathrm{Ca}^{2+}$ (Lytton et al., 1991). After intracellular $\mathrm{Ca}^{2+}$ was released by Tg, W-7 could not elevate $\left[\mathrm{Ca}^{2+}\right]_{i}$ any more in our experiments, so ER play a pivotal role in $\left[\mathrm{Ca}^{2+}\right]_{i}$ oscillation of Hela cells. W-7 is a documented inhibitor of calmodulin which is a receptor of $\mathrm{Ca}^{2+}$ (Nishikawa et al., 1980), inhibits $\mathrm{Ca}^{2+} /$ calmodulin activated phosphodiesterase and myosin light chain kinase and has been shown to alter many calmodulin-dependent cellular processes in different cell types. For example, W-7 has been shown to inhibit angiotensin II- or ionomycin-induced $\mathrm{Ca}^{2+}$ entry in human mesangial cells (Mene et al., 1996), inhibit vesicular $\mathrm{Ca}^{2+}$ uptake in Dictyostelium (Groner and Malchow, 1996), suppress sarcoplasmic reticulum $\mathrm{Ca}^{2+}$ uptake in vascular smooth muscle (Stout and Silver, 1992), and deplete internal $\mathrm{Ca}^{2+}$ stores in FRTL-5 thyroid cells (Morishima et al., 2002). In our experiments, $300 \mu \mathrm{M} \mathrm{W}-7$ caused instant elevation of $\left[\mathrm{Ca}^{2+}\right]_{\mathrm{i}}$ and rapid demise of Hela cells which was verified to be a necrosis-like apoptosis without mitochondria involvement, but through a new pathway-ER pathway.

Calpain, which are cytosolic calcium-activated neutral cysteine endopeptidases, upon activation by elevated intracellular calcium, is known to translocate from the cytosol to the ER membrane (Ito et al., 1987), where it may cleave procaspase12 and PTP-1B (Nakagawa et al., 2000) as was verified in our experiments. After incubation of $300 \mu \mathrm{M}$ W-7, PTP-1B in Hela cells was degenerated (Fig. 4B), hinted the activation of calpain by $\mathrm{Ca}^{2+} .30 \mu \mathrm{M}$ calpeptin (inhibitor of calpain) stopped assuredly the cleavage of procaspase-12 (Fig. 4B) and abolished apoptosis induced with W-7 (Fig. 4C and 4D), turned to the opposite direction-necrosis. This means the rapid apoptosis of Hela cells proceeded only through the ER pathway.

Although ER is the main intracellular $\mathrm{Ca}^{2+}$ store, mitochondria also take up and release $\mathrm{Ca}^{2+}$ very efficiently and are often strategically located close to $\mathrm{Ca}^{2+}$ sources (Rizzuto et al., 1998). Calreticulin is a $46 \mathrm{kDa} \mathrm{Ca}^{2+}$-binding chaperone that interacts in a $\mathrm{Ca}^{2+}$-dependent fashion with several ER resident proteins, such as unfolded glycoproteins and $\mathrm{Ca}^{2+}$ transporters at the ER membrane (Michalak et al., 1999), its overexpression can increase $\mathrm{Ca}^{2+}$ fluxes across the ER but decreases mitochondrial $\mathrm{Ca}^{2+}$ (Arnaudeau et al., 2002). In our experiments, calreticulin increased immediately accompany the elevation of $\left[\mathrm{Ca}^{2+}\right]_{\mathrm{i}}$, then decreased at $30 \mathrm{~min}$ after $\mathrm{W}-7$ addition (Fig. 4B), the decrease might attribute to the proteolysis of calreticulin in latter stage of apoptosis. In the long run, an increase in calreticulin appears to be deleterious for the cell, despite the reduction in $\mathrm{Ca}^{2+}$ influx that compensates for the increased $\mathrm{Ca}^{2+}$ release from the ER. In our experiments, swelling of mitochondria and ER emerged at 30 min after W-7 addition (Fig. 2), as might be caused by high $\mathrm{Ca}^{2+}$ microdomains around mitochondria.

Hitomi et al (Hitomi et al., 2004). found that caspase-3, not caspase-9 (a known mitochondrial apoptotic mediator), was mainly activated by ER stress, suggested that activation of ER-resident caspase-12 indirectly activates cytoplasmic 


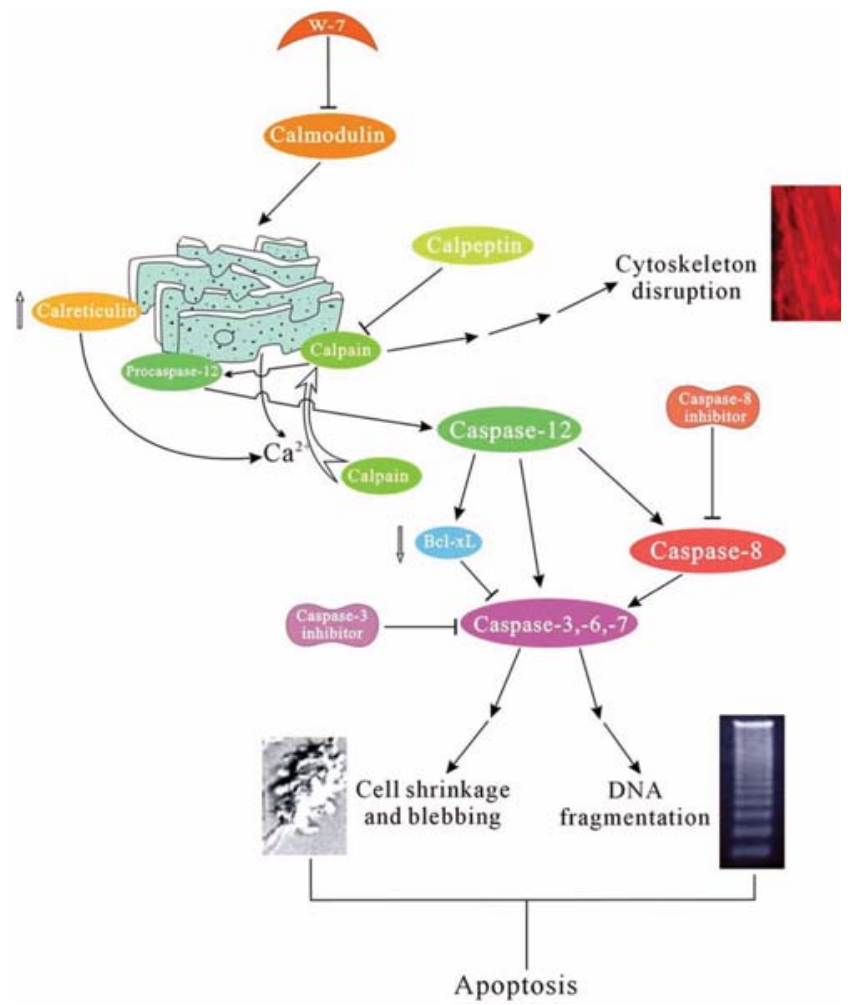

Fig. 6. ER pathway involved in the necrosis-like apoptosis of Hela cells. $300 \mu \mathrm{M} \mathrm{W}-7$ targeted calmodulin in cytoplasm, induced ER stress which increased calreticulin immediately, increased calreticulin promoted release of $\mathrm{Ca}^{2+}$ from ER, which was the main cause of $\left[\mathrm{Ca}^{2+}\right]_{\mathrm{i}}$ oscillation. Activated calpain induced by $\left[\mathrm{Ca}^{2+}\right]_{\mathrm{i}}$ oscillation translocated from cytoplasm to ER membrane where procaspase- 12 was cleaved. Caspase- 12 then activated downstream caspases, such as caspase-8 (activation of caspase-9 was not detected), caspase-3, and executed apoptosis (cell shrinkage and blebbing, DNA internucleosomal fragmentation). Together with other proteins, activated calpain also induced disruption of cytoskeleton in the early stage of apoptosis.

caspase-3. Our results coincided with this report. Downstream caspases, such as caspase- 8 and casapase- 3 were activated, but cleavage of procaspase-9 and activity elevation of caspase-9 was not detected (Fig. 1D and 4B). The procaspase9 band decreases substantially after 120 minutes without increase of caspase-9 band in Fig. 4B, this may be results of protein degeneration of proteins after necrosis of Hela cells rear to apoptosis.

Calpain also has been proposed to play a role in regulating normal signal transduction processes by cleaving cytoskeletal proteins (Liu and Schnellmann, 2003). In our experiments, cytoskeleton disrupted in apoptotic and necrotic Hela cells, $\beta$ actin was degenerated, but no degeneration of $\beta$-tubulin was measured by western blotting, so $\beta$-tubulin was used as invariant control in western blotting. Calpain is also responsible for cleaving the loop region in Bcl-xL which is antiapoptotic molecule of Bcl-2 family and, therefore, turning an antiapoptotic molecule into a proapoptotic molecule (Tornquist, 1993). Our experimental data coincided with this conclusion, Bcl-xL decreased along with incubation time of W-7 (Fig. 4B).

The molecular pathway of this rapid apoptosis may be depicted as follow (Fig. 6): W-7 targeted calmodulin in cytosol, induced ER stress which increased calreticulin immediately, increased calreticulin promoted release of $\mathrm{Ca}^{2+}$ from ER which was the main cause of $\left[\mathrm{Ca}^{2+}\right]_{i}$ oscillation, activated calpain by $\left[\mathrm{Ca}^{2+}\right]_{\mathrm{i}}$ oscillation translocated from cytosol to ER membrane where procaspase-12 was cleaved. Caspase-12 activated downstream caspases, such as caspase-8 (activation of caspase-9 was not detected), caspase-3, and executed apoptosis. Activated calpain together with other proteins also induced disruption of cytoskeleton.

Experiments demonstrated that ER is a primary target in various acute disorders and degenerative diseases of the brain, prolonged ER stress is linked to the pathogenesis of these disorders (Paschen, 2003). Studying mechanisms of ER pathway is helpful to facilitate the search for drugs capable of blocking the pathological process directly at an early stage.

In conclusion, $300 \mu \mathrm{M} \mathrm{W-7} \mathrm{induced} \mathrm{instant} \mathrm{necrosis-like}$ apoptosis seldom reported. This instant apoptosis of Hela cells was not mediated by mitochondria pathay or death receptor pathway, but by ER pathway. Apoptosis and necrosis can not explain all the cell death types, there are several forms of cell death between typical apoptosis and necrosis, such as paraptosis and necrosis-like apoptosis reported here by us.

Acknowledgment We thank Prof. Yeguang CHEN (Tsinghua University) and Dr. Shangfeng LIU (Tsinghua University) for their comments on manuscript, Ms. Jing DU (Tsinghua University) for her help in experiments, Mr. Jiyong ZHANG for his help on manuscript writing. This work was supported by postdoctoral grant of China (No. 023205004).

\section{References}

Arnaudeau, S., Frieden, M., Nakamura, K., Castelbou, C., Michalak, M. and Demaurex, N. (2002) Calreticulin differentially modulates calcium uptake and release in the endoplasmic reticulum and mitochondria. J. Biol. Chem. 277, 46696-46705.

Berridge, M. J., Bootman, M. D. and Lipp, P. (1998) Calcium-a life and death signal. Nature 395, 645-648.

Berridge, M. J., Lipp, P. and Bootman, M. D. (2000) The versatility and universality of calcium signalling. Nat. Rev. Mol. Cell. Biol. 1, 11-21.

Chen, Y., Douglass, T., Jeffes, E. W., Xu, Q., Williams, C. C., Arpajirakul, N., Delgado, C., Kleinman, M., Sanchez, R., Dan, Q., Kim, R. C., Wepsic, H. T. and Jadus, M. R. (2002) Living T9 glioma cells expressing membrane macrophage colonystimulating factor produce immediate tumor destruction by polymorphonuclear leukocytes and macrophages via a "paraptosis"-induced pathway that promotes systemic immunity against intracranial T9 gliomas. Blood 100, 1373-1380.

Groner, M. and Malchow, D. (1996) Calmodulin-antagonists inhibit vesicular $\mathrm{Ca}^{2+}$ uptake in Dictyostelium. Cell Calcium 19, 105-111. 
Hitomi, J., Katayama, T., Taniguchi, M., Honda, A., Imaizumi, K. and Tohyama, M. (2004) Apoptosis induced by endoplasmic reticulum stress depends on activation of caspase-3 via caspase-12. Neurosci. Lett. 357, 127-130.

Ito, M., Tanaka, T., Nunoki, K., Hidaka, H. and Suzuki, K. (1987) The $\mathrm{Ca}^{2+}$-activated protease (calpain) modulates $\mathrm{Ca}^{2+} /$ calmodulin dependent activity of smooth muscle myosin light chain kinase. Biochem. Biophys. Res. Commun. 145, 13211328.

Jan, C. R. and Tseng, C. J. (2000) W-7 induces $\left[\mathrm{Ca}^{2+}\right]_{\mathrm{i}}$ increases in Madin-Darby canine kidney (MDCK) cells. J. Pharmcol. Exp. Ther. 292, 358-365.

Kijima, Y., Ogunbunmi, E. and Fleischer, S. (1991) Drug action of thapsigargin on the $\mathrm{Ca}^{2+}$ pump protein of sarcoplasmic reticulum. J. Biol. Chem. 266, 22912-22918.

Liu, M. J., Wang, Z., Li, H. X., Wu, R. C., Liu, Y. Z. and Wu Q. Y. (2004) Mitochondrial dysfunction as an early event in the process of apoptosis induced by woodfordin I in human leukemia K562 cells. Toxicol. Appl. Pharmacol. 194, 141-155.

Liu, X. and Schnellmann, R. G. (2003) Calpain mediates progressive plasma membrane permeability and proteolysis of cytoskeleton-associated paxillin, talin, and vinculin during renal cell death. J. Pharmacol. Exp. Ther. 304, 63-70.

Liu, X., Kim, C. N., Yang, J. and Jemmerson, R. (1996) Induction of apoptotic program in cell-free extracts: Requirement for dATP and cytochrome $c$. Cell 86, 147-157.

Lytton, J., Westlin, M. and Hanley, M. R. (1991) Thapsigargin inhibits the sarcoplasmic or endoplasmic reticulum Ca-ATPase family of calcium pumps. J. Biol. Chem. 266, 17067-17071.

Mene, P., Pugliese, F. and Cinotti, G. A. (1996) Regulation of capacitative calcium influx in cultured human mesangial cells: roles of protein kinase $\mathrm{C}$ and calmodulin. J. Am. Soc. Nephrol. 7, 983-990.

Michalak, M., Corbett, E. F., Mesaeli, N., Nakamura, K. and Opas, M. (1999) Calreticulin: one protein, one gene, many functions. Biochem. J. 344, 281-292.

Morishima, N., Nakanishi, K., Takenouchi, H., Shibata, T. and Yasuhiko, Y. (2002) An endoplasmic reticulum stress-specific caspase cascade in apoptosis. Cytochrome c-independent activation of caspase- 9 by caspase-12. J. Biol. Chem. 277, 34287-34294.
Nakagawa, T., Zhu, H., Morishima, N., Li, E., Xu, J. and Yankner, B. A. (2000) Caspase-12 mediates endoplasmicreticulum-specific apoptosis and cytotoxicity by amyloid-beta. Nature 403, 98-103.

Nishikawa, M., Tanaka, T. and Hidaka, H. (1980) $\mathrm{Ca}^{2+}-$ calmodulin-dependent phosphorylation and platelet secretion. Nature 287, 863-865.

Paschen, W. (2003) Endoplasmic reticulum: a primary target in various acute disorders and degenerative diseases of the brain. Cell Calcium 34, 365-383.

Reddy, R., Buckley, S., Doerken, M., Barsky, L., Weinberg, K., Anderson, K. D., Warburton, D. and Driscoll, B. (2004) Isolation of a putative progenitor subpopulation of alveolar epithelial type 2 cells. Am. J. Physiol. Lung Cell. Mol. Physiol. 286, 658-667.

Rizzuto, R., Pinton, P., Carrington, W., Fay, F. S., Fogarty, K. E. and Lifshitz, L. M. (1998) Close contacts with the endoplasmic reticulum as determinants of mitochondrial $\mathrm{Ca}^{2+}$ responses. Science 280, 1763-1766.

Single, B., Leist, M. and Nicotera, P. (1998) Simultaneous release of adenylate kinase and cytochrome c in cell death. Cell Death Differ. 5, 1001-1003.

Stout, M. A. and Silver, P. J. (1992) Calcium transport by sarcoplasmic reticulum of vascular smooth muscle: II. Effects of calmodulin and calmodulin inhibitors. J. Cell Physiol. 153, 169-175.

Thastrup, O., Cullen, P. J., Drobak, B. K., Hanley, M. R. and Dawson, A. P. (1990) Thapsigargin, a tumor promoter, discharges intracellular $\mathrm{Ca}^{2+}$ stores by specific inhibition of the endoplasmic reticulum $\mathrm{Ca}^{2+}$-ATPase. Proc. Natl. Acad. Sci. USA 87, 2466-2470.

Tornquist, K. (1993) Activation of calcium entry by cyclopiazonic acid in thyroid FRTL-5 cells. Cell Calcium 14, 411-417.

Van, C. S. and Van, D. B. W. (2002) Morphological and biochemical aspects of apoptosis, oncosis and necrosis. Anat. Histol. Embryol. 31, 214-223.

Veselska, R., Zitterbart, K., Jelinkova, S., Neradil, J. and Svoboda, A. (2003) Specific cytoskeleton changes during apoptosis accompanying induced differentiation of HL-60 myeloid leukemia cells. Oncol. Rep. 10, 1049-1058. 